\title{
ANTINOCICEPTIVE ACTIVITY OF METHANOLIC EXTRACT OF THE LEAVES OF FERONIA LIMONIA LINN
}

\author{
MONI RANI SAHA ${ }^{1}$, SHEIKH ZAHIR RAIHAN ${ }^{1 *}$, AKM SHAHIDUR RAHMAN ${ }^{2}$
}

Department of Pharmacy, Stamford University of Bangladesh, Dhaka-1217¹, Bangladesh, Department of Pharmacology and Therapeutics, Khwaja Yunus Ali Medical College, Enayetpur Sharif, Post- Enyetpur, Sirajgonj-6751 ${ }^{2}$

\begin{abstract}
The antinociceptive activity of the methanolic extract of the leaves of Feronia limonia Linn. (Family Rutaceae) was investigated using acetic acid-induced writhing model and tail flick test in swiss albino mice. The extract produced about 26.01\% ( $p<0.01), 39.88 \%(p<0.01)$ and $57.07 \%(p<0.01)$ writhing inhibition at the dose of 100,200 and $400 \mathrm{mg} / \mathrm{kg}$ of body weight respectively, which was comparable to the standard drug diclofenac sodium where the inhibition was about $63.58 \%$ ( $p<$ $0.01)$ at the dose of $25 \mathrm{mg} / \mathrm{kg}$ of body weight. All doses of extracts significantly $(p<0.05)$ increased latency of flick tail in tail immersion method. The methanolic extract showed dose dependent antinociceptive activity in both type of test in swiss albino mice. Phytochemical investigations of the leaves extract indicate the presence of tannins, saponins, steroids, alkaloids and flavonoids. The preliminary study of the methanolic extract showed antinociceptive activity in both writhing and tail flick test in mice.
\end{abstract}

Key words: Feronia limonia, antinociceptive activity, acetic acid-induced writhing, tail flick, phytochemical test.

(Bangladesh J Physiol Pharmacol 2010; 26(1\&2) : 21-24)

\section{INTRODUCTION}

Feronia limonia Linn. (Family Rutaceae, Bengali Kathbel, English Wood apple) is a moderate-sized tree with straight sharp strong spines, $1.2-3.7 \mathrm{~cm}$ long, which is widely distributed throughout Bangladesh, India, Ceylon and Java ${ }^{1,2,3}$. The fruits of the plant are edible and considered to be a stomachie, astringent, diuretic, cardiotonic and tonic to liver and lungs ${ }^{3}$. Its fruit is antiscorbutic, carminative, stimulant to the digestive system. Leaves are astringent; used for indigestion, flatulence, diarrhoea, dysentery and haemorrhoids. The leaves and stem bark contain the coumarins, luvangetin, xanthotoxin and limonin and the steroids, sitosterol and sitosterol-O-beta-D-glucoside. Antifungal compounds, psoralene from stembark; xanthotoxin and osthenol from root bark and 2,6-dimeth-oxybenzo-quinone from the fruit shell are reported. Leaves are astringent, carminative and given in indigestion, flatulence, diarrhea, dysentery, vomiting, hiccup and haemorrhoids ${ }^{1}$. The plant is also used in diabetes ${ }^{3}$ and

Address of Correspondence: Sheikh Zahir Raihan, Lecturer, Department of Pharmacy, Stamford University of Bangladesh, 51-Siddeshwari Road, Dhaka-1217, Cell: 01937992538, E-mail: sheikhzahir_du@yahoo.com snake bite ${ }^{4}$. Antitumor acidic polysaccharides has been isolated from the fruit part of this plant species ${ }^{5}$. The stem bark contains several flavanone having antimicrobial properties ${ }^{6}$. Acetone extract of dried leaves showed potent mosquito larvicidal activity ${ }^{7}$. The present report describes the antinociceptive activity of the leaves and exploration of the justification of its use as folk medicine.

\section{MATERIALS AND METHODS}

Plant materials and extractions:

Leaves of Feronia limonia L. were collected from Ramkantopur at Pabna district, Rajshahi division on January 2010 and taxonomically identified by Bangladesh National Herbarium, Dhaka (accession number 31105). The leaves were dried by shade drying for 15 days and then again dried in a hot air oven at $40^{\circ} \mathrm{C}$ for 1 hour to remove moisture. Fine powder was obtained after grinding. The leaves were extracted by hot extraction method where100gm powder was macerated with $250 \mathrm{ml}$ methanol. The container with its contents was sealed and kept for a period of 7 days accompanying occasional shaking and stirring. The whole mixture then underwent 
a coarse filtration by a piece of clean, white cotton material. Then it was filtered through filter paper. The filtrate (methanol extract) thus obtained was evaporated by using a suitable rotary evaporator to get a viscous mass. The viscous mass was then kept at room temperature under a ceiling fan to get a dried extract (about 10\% yields). The extract (MFL) thus obtained was used for antinociceptive activity.

\section{Phytochemical Tests}

Phytochemical investigations of the leaves extract indicate the presence of tannins, saponins, steroids, alkaloids and flavonoids. The crude methanolic extract of the leaves of Feronia limonia was tested for its different chemical groups as tannins, saponins, steroids, alkaloids and flavonoids by the phytochemical analysis processes described by Evans ${ }^{8}$.

\section{Animals}

Young Swiss-albino mice of either sex, aged 3-4 weeks, average weight 20-25 gm were purchased from the Animal Research Branch of the International Centre for Diarrhoeal Disease and Research, Bangladesh (ICDDR, B). The animals were kept at animal house for adaptation after their purchase under standard laboratory conditions (relative humidity 55-65\%, room temperature $25.0 \pm 2.0^{\circ} \mathrm{C}$ and 12 hours light: dark cycle) and fed with standard diets (ICDDR, B formulated) and had free access to tap water.

\section{Antinociceptive activity study using acetic acid- induced writhing assay:}

Antinociceptive activity of the methanolic extract of Feronia limonia was tested using the model of acetic acid induced writhing in mice ${ }^{9}$. The experimental animals were randomly divided into five groups, each consisting of five animals. Group I was treated as 'control group' which received $1 \%(\mathrm{v} / \mathrm{v})$ Tween-80 solution in water by p.o. route; group II was treated as 'positive control' and was given the standard drug Diclofenac sodium at dose of $25 \mathrm{mg} / \mathrm{kg}$ of body weight; group III, IV and V were test groups and were treated with methanolic extracts of Feronia limonia at the doses of 100, 200 and $400 \mathrm{mg}$ per $\mathrm{kg}$ of body weight respectively. Standard drug and extracts were administered orally, 30 min prior to acetic acid $(0.7$ $\%)$ injection. Then after an interval of $15 \mathrm{~min}$, the number of writhes (squirms) was counted for $5 \mathrm{~min}$.

\section{Antinociceptive activity study using tail-flick test:}

Immersion of an animal's tail in hot water provokes an abrupt movement of the tail and sometimes the recoiling of the whole body. Again, it is the reaction time that is the time to flick the tail from hot water which is monitored $^{10}$. The extract was administered orally at three doses (100, 200 and 400 mg/kg body weight) using
Diclofenac Sodium (25mg/kg) as standard. The distal 2$3 \mathrm{~cm}$ portion of mouse-tail was immersed in hot water maintained at $55 \pm 0.5^{\circ} \mathrm{C}$. The screening cut-off time was $5 \mathrm{sec}$, while the test cut-off time was $10 \mathrm{sec}$. The post drug reaction times were measured at 0, 30, 60 and 90 minutes later. The time to flick the tail from water (reaction time) was recorded. A maximum immersion time of 10 seconds was maintained to prevent thermal injury to the animals. A significant increase in reaction time compared with control animals was considered a positive analgesic response.

\section{Statistical analysis}

Statistical analysis was done with SPSS statistics 17.0 using one way ANOVA followed by Dunett $t$ test. Significance level of $<0.05$ was considered as significant.

\section{RESULTS AND DISCUSSION}

In the statistical analysis all groups show significant $(p<0.05)$ antinociceptive activity compared to the control group (Table-1 and Table-2). The preliminary phytochemical screening of leaves extract of Feronia limonia showed the presence of tannins, saponins, steroids, alkaloids and flavonoids in our laboratory. These compounds have well known anti-inflammatory effects ${ }^{11}$. In writhing assay the extract produced about 26.01\% ( $\mathrm{P}<$ 0.01), 39.88\% ( $P<0.01)$ and 56.07\% ( $P<0.01)$ writhing inhibition at the kose of 100,200 and $400 \mathrm{mg} / \mathrm{kg}$ of body weight respectively, which was comparable to the standard drug diclofenac sodium where the inhibition was about $63.58 \%(P<0.01)$ at the dose of $25 \mathrm{mg} / \mathrm{kg}$ of body weight. Acetic acid induced writhing is a sensitive method for screening peripheral analgesic effect of compounds. Increased levels of PGE2 and PGF2 $\alpha$ in the peritoneal fluid have been reported to be responsible for pain sensation caused by intraperitoneal administration of acetic acid ${ }^{12,13}$. Prostaglandins elicit

\section{Table-I}

Effect of methanolic leaves extract of F. limonia on acetic acid induced writhing in mice:

\begin{tabular}{lcc}
\hline Treatment $(\mathrm{mg} / \mathrm{kg})$ & $\begin{array}{c}\text { Number of } \\
\text { writhings }\end{array}$ & $\begin{array}{c}\% \\
\text { inhibition }\end{array}$ \\
\hline Control & $34.60 \pm 3.85$ & - \\
Diclofenac (50) & $12.60 \pm 1.81^{\star}$ & 63.58 \\
MFL (100) & $25.60 \pm 2.30^{\star}$ & 26.01 \\
MFL (200) & $20.80 \pm 5.81^{\star}$ & 39.88 \\
MFL (400) & $15.20 \pm 1.92^{\star}$ & 56.07 \\
\hline
\end{tabular}

$\mathrm{n}=5$. The observation are mean S.E.M. ${ }^{*} p<0.05$, as compared to control. (ANOVA followed by Dunnett $t$ test). MFL $=$ Metahnolic leaves extract of Feronia limoina. 
Table-2

Effect of MFL (100, 200 AND $400 \mathrm{mg} / \mathrm{kg})$ on Tail immersion method in mice.

\begin{tabular}{lcccc}
\hline Treatment $(\mathrm{mg} / \mathrm{kg})$ & \multicolumn{2}{c}{ Latency to flick tail (second) } \\
& $0 \mathrm{~min}$ & $30 \mathrm{~min}$ & $60 \mathrm{~min}$ & $90 \mathrm{~min}$ \\
\hline Control & $1.90 \pm 0.41$ & $1.94 \pm 0.18$ & $2.19 \pm 0.14$ & $1.85 \pm 0.16$ \\
Diclofenac (25) & $1.79 \pm 0.15$ & $5.74 \pm 0.30$ & $7.26 \pm 0.26^{\star}$ & $6.88 \pm 0.16^{\star}$ \\
MFL (100) & $1.83 \pm 0.60$ & $2.63 \pm 0.38$ & $3.16 \pm 0.15^{\star}$ & $2.98 \pm 0.12^{*}$ \\
MFL (200) & $1.72 \pm 0.12$ & $2.48 \pm 0.09$ & $3.50 \pm 0.24^{*}$ & $4.10 \pm 0.38^{\star}$ \\
MFL (400) & $1.85 \pm 0.12$ & $2.51 \pm 0.16$ & $4.15 \pm 0.23^{*}$ & $4.66 \pm 0.28^{\star}$ \\
\hline
\end{tabular}

$\mathrm{n}=5$. The observation are mean S.E.M. ${ }^{*} \mathrm{p}<0.05$, as compared to control. (ANOVA followed by Dunnett $t$ test). $M F L=$ Metahnolic leaves extract of Feronia limoina.

pain by direct stimulation of sensory nerve endings and also sensitize sensory nerve endings to other pain provoking stimuli14. Moreover, prostaglandins especially PGE1 was reported to act on cell membrane during inflammatory conditions leading to changes in lipoprotein structure of cell membrane. This causes destabilization of cell membrane furthering to degenerative cellular changes $^{15}$. The abdominal constriction is related to the sensitization of nociceptive receptors to prostaglandins. It is therefore possible that extract produced analgesic effect may be probably due to the inhibition of synthesis or action of prostaglandin. Therefore, it is likely that Feronia limonia leaves extracts might suppress the formation of these substances or antagonize the action of these substances and thus exerts its peripheral analgesic activity in acetic acid-induced writhing test.

The tail-flick method originally described by Woolfe and Mac Donald ${ }^{16}$ has been found to be suitable for the evaluation of centrally acting but not peripherally acting analgesics. The nociceptors seem to be sensitized by

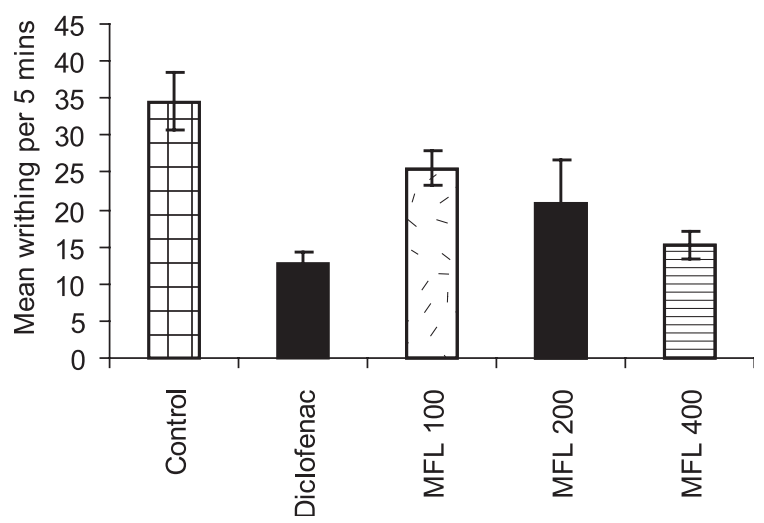

Fig.-1: Effect of methanolic leaves extract of F.limonia on acetic acid induced writhing in mice. MFL = Methanolic extract of Feronia limonia. Data are expressed as mean \pm SEM

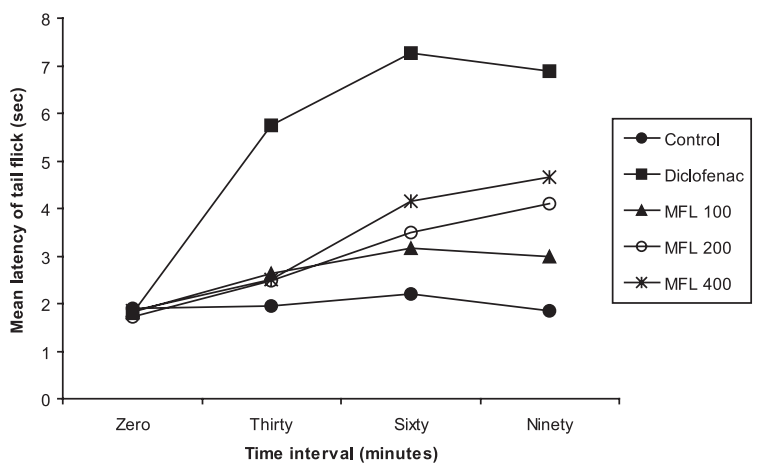

Fig.-2: Effect of methanolic leaves extract of F.limonia in tail flick assay. MFL = Methanolic extract of F.limonia. Data are expressed as mean SEM.

sensory nerves. A significant increase in the reaction time for tail flick method indicated the analgesic effect by methanolic extract of F.limonia. This elucidates the involvement of central mechanism in analgesic action. On the basis of the result of acetic acid induced writhing test and tail-flick test, it can be concluded that the methanolic extract of the leaves of Feronia limonia might possess an antinociceptive activity. The study also provides a strong evidence for the use of the leaves $F$. limonia in folkloric treatment as analgesic agent. The activity may be due to the presence of one or more phytochemical constituents present in the extract further study is warranted, for isolation of the constituents responsible for the activity and also to explore the exact mechanism of action of the activity.

\section{CONCLUSION}

In conclusion, it can be suggested that the crude methanolic extract of Feronia limonia Linn. may possess antinociceptive activity, which correlate well with the traditional use of the plant. Therefore, further pharmacological investigations of bioactivity guided phytochemical studies are required to find out the actual 
constituents responsible for antinociceptive action of the extract of Feronia limonia Linn.

\section{ACKNOWLEDGEMENT}

We are grateful to Professor Dr. Abdul Ghani, Chairman, Department of Pharmacy, Stamford University of Bangladesh for give us a scope to utilize his Pharmacology Research Laboratory for phytochemical $\&$ biological investigation of the leaves extract of Feronia limonia Linn.

\section{REFERENCES}

1. Ghani A. Medicinal plants of Bangladesh, Second edition, Dhaka-1000: Asiatic Society of Bangladesh 2003; pp229.

2. Yusuf M, Chowdhury JU, Wahab MA, Begum J. Medicinal plants of Bangladesh, Dhaka-1205: Bangladesh Council of Scientific and Industrial Research 1994; 112-114.

3. Kirtikar KR, Basu BD. Indian medicinal plants, vol. I. Bishen Singh Mahendra Pal Singh, India. 1993; 496-498.

4. Agrawal A, Siddique IR, Singh J. Coumarins from the roots of Feronia limonia. Phytochemistry 1989; 28, 1229-1232.

5. Saima Y, Das AK, Sarkar KK, Sen AK, Sur P. An antitumor pectic polysaccharide from Feronia limonia. Int $\mathrm{J}$ Biol Macromol. 2000; 27: 333-5.

6. Rahman MM, Gray Al. Antimicrobial constituents from the stem bark of Feronia limonia. Phytochemistry 2002; 59: 73-7.

7. Rahuman AA, Gopalakrishnan G, Ghouse BS, Arumugam $\mathrm{S}$, Himalayan B. Effect of Feronia limonia on mosquito larvae. Fitoterapia, 2000; 71: 553-555.
8. Evans WC. Trease and Evan's Textbook of Pharmacognosy. 13th ed., Cambridge University Press, London, 1989; p. 546.

9. Whittle BA. The use of changes in capillary permeability in mice to distinguish between narcotic and non-narcotic analgesics. Br J Pharmacol Chemother 1964; 22: 246

10. Turner RA. Screening methods in Pharmacology, Academic Press, 1971; 100-113.

11. Park EH, Kahng JH, Lee SH, Shin KH. (2001) An antiinflammatory principle from cactus. Fitoterapia. 72, 288290.

12. Derardt R, Jougney S, Delevalcee F and Falhout M. Release of prostaglandins $E$ and $F$ in an algogenic reaction and its inhibition. Eur J Pharmacol, 1980; 51: 17-24.

13. Collier HO, Dinneen LC, Johnson CA, Schneider C. The abdominal constriction response and its suppression by analgesic drugs in mouse. Br J Pharmacol. 1968; 32: 295310.

14. Campbell WB. Lipid-derived autacoids: Eicosanoids and platelet activating factor. In: Goodman and Gilman's The pharmacological basis of therapeutics. Gilman AG, Rall TW, Neis AS, Taylor P (eds). 8th ed. New York, Pergamon Press, 1991, pp 607-08.

15. Rao AB, Sisodia P, Sattur PB. Erythrocyte membrane stabilisation by enfenamic acid. Indian J Exp Biol. 1987; 25: 489-90.

16. Woolfe G, MacDonald AD. The evaluation of the analgesic action of pethidine hydrochloride. J Pharmacol Exp. Ther. 1994; 80, 300-307. 